\title{
RELAÇÕES VIRTUAIS DE CONSUMO: PERSPECTIVAS DE DIREITOS NO E-COMMERCE
}

\section{VIRTUAL CONSUMER RELATIONS: PROSPECTS OF RIGHTS IN E-COMMERCE}

\begin{abstract}
VITOR HugO dO AMARAL FERREIRA Advogado, Professor universitário, Docente no Curso de Direito, do Centro Universitário Franciscano (UNIFRA), Mestre em Integração Latino Americana (UFSM), Coordenador do Grupo de Estudos Política e Sociedade de Consumo, Membro
\end{abstract}

Diretor do Instituto Brasileiro de Política e Direito do Consumidor.

\section{RESUMO}

O presente estudo perfaz uma abordagem crítica em face às relações de consumo atuais e a forma como interagem com a tecnologia. Sabe-se que o comércio eletrônico é um fenômeno recente e crescente decorrente da tecnologia da informação que evolui a passos largos. Neste enfoque, busca-se suprir as lacunas legislativas do Código de Defesa do Consumidor (CDC) quanto ao consumo virtual $e$ estender a proteção aos consumidores virtuais. Neste contexto, importante a abordagem quanto ao consumo via internet e as implicações decorrentes desse novo meio de consumir em contraste com os já conhecidos elementos característicos da relação de consumo presencial e os conceitos principiológicos aplicáveis ao comércio eletrônico. Em que pese analisa-se 0 Anteprojeto de Atualização do $\operatorname{CDC}$ que propõe mudanças a este, incluindo o comércio eletrônico e suas peculiaridades à extensão do código protetivo. Por fim, o tema é enfrentado a partir da análise do entendimento e posicionamento do Tribunal de Justica do Rio Grande do Sul diante das decisões exaradas sobre o comércio eletrônico e a aplicabilidade do CDC.

Palavras-chave: comércio eletrônico; direito do consumidor; atualização do CDC.

\begin{abstract}
The present study makes a critical approach in the face of today's consumer relations and how they interact with technology. It is known that electronic commerce is a recent phenomenon due to the growing information technology evolving at a rapid pace. In this approach, we seek to address the loopholes of the Consumer Defense Code (CDC) and virtual consumption and extend the protection of virtual consumers. In this context, important approach to the consumer via the Internet and the implications of this new way of consuming in contrast to the known characteristic features of the consumption and the presence concepts applicable to electronic commerce. Despite analyzes the Draft Update of the CDC which proposes changes to this, including electronic commerce and its peculiarities to the extent of protective code. Finally, the issue is tackled from the analysis of the understanding and positioning of the Court of Rio Grande do Sul on the decisions entered on electronic commerce and the applicability of the CDC.
\end{abstract}

Keywords: electronic Commerce; consumer Law; CDC update. 
ISSN 2316-3054

\section{SUMÁRIO}

INTRODUÇÃO; 1 AS RELAÇÕES DE CONSUMO EM TEMPOS DE INTERNET; 1.1 Elementos da relação de consumo e o e-consumer na relação virtual consumerista; 1.2 Vulnerabilidade e nulidade: questões contratuais; 2 PREMISSAS LEGAIS: O ANTEPROJETO DE ATUALIZAÇÃO DO CÓDIGO DE DEFESA DO CONSUMIDOR E O TJRS FRENTE ÀS LACUNAS JURÍDICAS DO E-COMMERCE; 2.10 Anteprojeto de atualização do Código de Defesa do Consumidor; 2.2 O Tribunal de Justiça do Rio Grande do Sul frente ao comércio eletrônico; CONCLUSÃO; REFERÊNCIAS

\section{INTRODUÇÃO}

Albergado pelos ditames e diretrizes constitucionais, o Código de Defesa do Consumidor (CDC) fundou-se nos pilares dos artigos $5^{\circ}$, inciso XXXII e 170, inciso V, da Constituição Federal, sendo que aquele prevê a promoção, por parte do Estado, da Defesa do Consumidor e este os princípios norteadores da atividade econômica, sendo um deles a defesa e proteção do consumidor.

Anteriormente à proteção conferida pelo CDC, havia grande disparidade entre o fornecedor e o consumidor, sendo que aquele possuía mais força frente a este devido à inexistência de uma lei que efetivasse a sua proteção de forma completa. Com a promulgação do CDC, tal paisagem mudou, trazendo maiores garantias e equilíbrio às relações de consumo.

Neste compasso, assim como a evolução do ser humano, o Direito do Consumidor deve evoluir, pois dele emanaram e continuam a surgir diversos ramos do consumo que hoje estão mais do que presentes no cotidiano da população consumidora.

Uma destas ramificações que merece destaque, objeto deste artigo, é o consumo virtual, o qual vem se disseminando velozmente. Não existe método mais fácil - e ao mesmo tempo mais perigoso - de comprar e consumir, do que por meio da internet. Perigoso? Arriscado, pois, mesmo com todo o aparato legal e protecionista que emana do Código de Defesa do Consumidor, identifica-se lacunas quanto aos novos métodos e meios de consumo.

Diante deste vácuo jurídico, é de se debater, analisar e tomar providências, já que diante do Anteprojeto de Atualização do Código de Defesa do Consumidor urge lançar questionamentos e também apontar possíveis soluções que levem ao preenchimento deste vazio legal.

Inegável é o fenômeno consumista e os benefícios trazidos pela invasão digital e a influência da rede mundial de computadores nos lares, tanto em âmbito nacional quanto internacional, especialmente quando o ponto cerne da questão é o direito do consumidor frente 
ISSN 2316-3054

ao recém surgido e imaturo consumidor virtual. Porém, este fica ainda mais vulnerável nesse novo meio, já que a confiabilidade daquele que consome frente ao que fornece, e a boa-fé esperada de suas virtuais relações de consumo ainda devem ser trabalhadas e melhoradas.

Como o CDC se baseia, além da aplicabilidade da lei, também em ditames principiológicos, impende referir que a confiabilidade e a boa-fé são princípios necessários às relações de consumo, sejam estas em âmbito físico ou eletrônico.

Neste cenário, busca-se por meio deste artigo, discutir as relações virtuais consumeristas, lançando questionamentos quanto ao tratamento do tema no Código de Defesa do Consumidor vigente, as propostas do Anteprojeto de Atualização do CDC e a prática do Tribunal de Justiça do Estado do Rio Grande do Sul no que tange ao comércio eletrônico.

\section{AS RELAÇÕES DE CONSUMO EM TEMPOS DE INTERNET}

Ao delimitar o presente estudo é necessário que se faça uma abordagem quanto à origem da Lei 8.078 de 11 de setembro de 1990, denominado Código de Defesa do Consumidor $(C D C)$. Anteriormente à existência deste, não havia garantias capazes e eficazes de sanar o abismo existente entre consumidor e fornecedor, já que as únicas fontes que poderiam, à época, trazer algum direito àquele eram a Constituição Federal de 1988 e o Código Civil, que deixavam de tratar a área em sua especificidade.

Anteriormente à edição do $\operatorname{CDC}$ e, ainda, à Constituição Federal, a proteção das obrigações contratuais e comerciais era regida pelo antigo Código Civil e pelo extinto Código Comercial. Mesmo que não definida como proteção do consumidor, as relações de consumo já tinham algum respaldo nessas codificações ainda que de forma esparsa e não objetiva. Deve-se atentar, porém, ao fato de que as relações de consumo eram entendidas como uma relação obrigacional comum, não distinguindo os tipos de obrigações e partes envolvidas.

Neste contexto, com a promulgação da Constituição Federal de 1988 (CF/88), passou-se a ter uma melhor visão sobre a proteção do consumidor, separando de vez o que outrora era tido simplesmente como uma relação obrigacional. Quando da sua entrada em vigor, a CF/88 estabeleceu a obrigação ao Estado em promover, na forma da lei, a defesa do consumidor, trazendo tal normativa como imperativo à elaboração do CDC. Obviamente que não se deve olvidar e ignorar as menções de proteção ao consumidor presentes à época no Código Civil de 
ISSN 2316-3054

1916. Ocorre, porém, que a CF/88 foi o principal marco para que se efetivasse de vez a proteção do consumidor, consolidando também dentre os princípios da ordem econômica a defesa do consumidor.

Sabe-se que o Direito está em constante evolução, seja para adequar-se às mudanças sociais, seja para acompanhar o surgimento de novos ramos da ciência. Tem-se que o CDC é relativamente novo se comparado a diversas outras codificações brasileiras. Assim como o Código Civil de 2002 e a CF de 1988, o CDC tem papel importante no desenvolvimento social e econômico no cenário atual. Tal importância se deve à veloz evolução de diversos ramos do Direito, em especial o Direito do Consumidor, cada vez mais atrelado às novas tecnologias, em especial a internet. ${ }^{1}$

Quando da edição do CDC, o Brasil passava por um processo de aperfeiçoamento das formas de comunicação a grandes distâncias e em tempo real. Em 1990, não só entrava em vigor o Código de Defesa do Consumidor, como também dava seus primeiros passos o que viria a ser a internet brasileira. É de se saber, a título histórico, que a internet como se conhece hoje não nasceu assim; fora um processo lento se comparado à evolução atual. ${ }^{2}$

Tratando da internet como se conhece hoje, esta "engatinhou" pela primeira vez, como bem observa Maria Eugênia Finkelstein ${ }^{3}$, em meados de 1969, quando os Estados Unidos passavam pela Guerra Fria. Inicialmente, a rede que antecedeu a internet era denominada Arpanet e, segundo a história, fora concebida para facilitar a comunicação entre os computadores militar americanos. Com o fim da guerra, as instituições privadas e grandes empresas viram a rede como um novo meio de negócios.

Dado o primeiro passo para a liberação civil da rede, surgiram as primeiras interligações, as quais originalmente eram usadas com fim acadêmico e de uso restrito de universidades. A partir daí, ao longo dos anos foram surgindo várias redes diferentes, que posteriormente dariam início à internet como se conhece.

No Brasil, a iniciativa fora dada pela Fundação de Amparo à Pesquisa no Estado de São Paulo (FAPESP), visando o intercâmbio e a troca de informações com outras Instituições mundo a

\footnotetext{
${ }^{1}$ FINKELSTEIN. Maria Eugenia Reis. Direito do comércio eletrônico. 2 ed. Rio de Janeiro: Elsevier, 2011.

2 SALGARELLI, Kelly Cristina. Direito do consumidor no comércio eletrônico: uma abordagem sobre a confiança e a boa-fé. São Paulo: Ícone, 2010.

${ }^{3}$ FINKELSTEIN. Maria Eugenia Reis. Direito do comércio eletrônico. 2. ed. Rio de Janeiro: Elsevier, 2011, p. 23.

REDESG / Revista Direitos Emergentes na Sociedade Global - www.ufsm.br/redesg v. 1, n. 1, jan.jun/2012
} 
ISSN 2316-3054

fora. Segundo aborda a doutrina "a ideia era estabelecer uma Rede para fins acadêmicos, de forma que pesquisadores pudessem compartilhar dados com instituições de outros países". ${ }^{4}$

Cerca de um ano mais tarde, era feita a primeira conexão entre estados no Brasil por meio da rede, sendo que esta, por manter uma linha internacional direta e conectada à FAPESP, possibilitou o acesso à internet às fundações de pesquisa e órgãos educacionais que viriam a se beneficiar do acesso. Não era possível ainda o acesso da população ao fenômeno da internet o qual somente fora liberado em $1995 .^{5}$

Com a ambição de liberar o acesso à população, no ano de 1995, os Ministérios das Comunicações e da Ciência e Tecnologia criaram a figura que seria o primeiro provedor de acesso privado à internet no Brasil. Teve início então a atual internet no Brasil e, consequentemente, o comércio eletrônico, que daria seus primeiros passos rumo à Rede Mundial de Consumo.

Após o nascimento da internet no Brasil, quase que ao mesmo tempo nasceu o comércio eletrônico - em proporções globais - o que posteriormente implicaria na relação entre fornecedor e consumidor no meio eletrônico.

Pela facilitação do acesso à internet, o consumidor da atualidade não mais precisa sair de casa para comprar determinado produto. Tudo que este deseja está a alguns cliques do mouse e preenchimento de alguns dados, possibilitando o consumo sem a necessidade de sair de casa. $^{6}$

Para bem conceituar comércio eletrônico, oportuna a definição dada por Maria Eugênia Finkelstein, a qual entende "que o comércio eletrônico nada mais é do que uma modalidade de compra a distância, na qual são recebidas e transmitidas informações por meio eletrônico". 7

O conceito de comércio eletrônico trazido por Denise Estella Tellini define "como o conjunto das transações contratuais efetuadas tendo como meio a internet ou qualquer outro sistema eletrônico que permita a troca simultânea de dados". ${ }^{8}$ Neste enfrentamento,

\footnotetext{
${ }^{4}$ SALGARELLI, Kelly Cristina. Direito do consumidor no comércio eletrônico: uma abordagem sobre a confiança e a boa-fé. $1^{\text {a }}$. ed. São Paulo: Ícone, 2010, p. 56.

${ }^{5}$ FINKELSTEIN. Maria Eugenia Reis. Direito do comércio eletrônico. 2. ed. Rio de Janeiro: Elsevier, 2011, p. 25.

${ }^{6}$ Ibidem.

${ }^{7}$ Ibidem, p. 38.

${ }^{8}$ TELLINI, Denise Estrella. Regime de Direito Internacional Privado na responsabilidade dos provedores de internet: (Content Services Providers e Intermediary Service Providers) pela qualidade dos serviços executados online. Porto Alegre: Sergio Antonio Fabris Ed., 2006, p. 45.

REDESG / Revista Direitos Emergentes na Sociedade Global - www.ufsm.br/redesg v. 1, n. 1, jan.jun/2012
} 
ISSN 2316-3054

depreende-se que o comércio eletrônico nada mais é do que toda atividade consumerista que usa da troca de informação e dados por meio do espaço virtual propiciado pela internet.

Imperioso referir que o comércio eletrônico como se vê na atualidade, em tese não possui qualquer regulação em território brasileiro, devendo o direito adaptar-se e moldar-se de acordo com entendimentos dos Tribunais e com as leis vigentes. Vale destacar que esta nova modalidade ou forma de consumir, torna-se perigosa na medida em que está sendo massivamente praticada, pois não há qualquer previsão desta no CDC ou em outras codificações. Porém, entende Kelly Cristina Salgarelli ${ }^{9}$ que:

Perfeitamente aplicável a estas relações o disposto no Código de Defesa do Consumidor, já que as figuras de fornecedor e consumidor encontram-se intactas, variando, apenas, o meio de contratação, que prescinde da forma escrita, tradicional, e dá origem a propostas e aceitações modernas, realizadas através de clicks e envio de mensagens eletrônicas.

Nesta senda, o comércio virtual não altera a figura de consumidor e fornecedor - apesar destes serem modernamente chamados de e-consumer e e-seller - pois se altera tão somente o meio e a forma da contratação, deixando intactas as figuras das partes envolvidas, tornando aplicável, apesar de não em sua total efetividade, o Código de Defesa do Consumidor. ${ }^{10}$

Importante ressalva deve ser feita, porém, quanto ao fato de que a aplicabilidade do CDC ao comércio eletrônico se dá apenas quando os contratos virtuais firmados são nacionais. Não se engloba os contratos internacionais, pois com a descentralização do território, antes físico, em que se davam as contratações, e sem a definição do tempo e espaço anteriormente bem apresentados pela doutrina e jurisprudência, não há mais como se falar em limites de nacionalidade e territorialidade, já que agora o lugar da conclusão dos contratos e negócios firmados são determinados pelas partes que contratam. ${ }^{11}$

Este é o cenário que permeia o objeto deste estudo, o qual será abordado na sequência a partir dos elementos da relação de consumo virtual e dos princípios da boa-fé e da confiabilidade.

\footnotetext{
9 SALGARELLI, Kelly Cristina. Direito do consumidor no comércio eletrônico: uma abordagem sobre a confiança e a boa-fé. $1^{\text {a }}$. ed. São Paulo: Ícone, 2010, p. 77.

${ }^{10}$ FINKELSTEIN. Maria Eugenia Reis. Direito do comércio eletrônico. 2. ed. Rio de Janeiro: Elsevier, 2011, p. 224.

11 SALGARELLI, Kelly Cristina. Direito do consumidor no comércio eletrônico: uma abordagem sobre a confiança e a boa-fé. São Paulo: Í́cone, 2010, p. 79.

REDESG / Revista Direitos Emergentes na Sociedade Global - www.ufsm.br/redesg v. 1, n. 1, jan.jun/2012
} 


\subsection{Elementos da relação de consumo e o e-consumer na relação virtual consumerista}

Basicamente, uma relação de consumo, de forma imperiosa, possui dois elementos que nunca deverão mudar: fornecedor e consumidor. Sem estas duas figuras basilares não há que se falar em relação de consumo. Há ainda que se dar atenção aos demais elementos, tais como motivação, oferta, vontade das partes e o próprio contrato em si.

Como forma de bem entender quais são os elementos da relação de consumo, destacase o entendimento dado por Bonatto ${ }^{12}$ :

São elementos da relação de consumo, segundo o Estatuto Protetivo: a) como sujeitos: o consumidor e o fornecedor; b) como objeto: produto ou serviço; c) como finalidade, caracterizando-se como elemento teleológico das relações de consumo: a aquisição ou a utilização do produto ou serviço, por parte do consumidor, como destinatário final.

Para que se possa falar de relação virtual de consumo, é necessário, anteriormente, conceituar o comércio eletrônico. A origem deste, segundo expõe Eduardo Weis Martins de Lima $^{13}$, remonta dos sistemas de televendas, os quais eram realizados por telefone. Esta definição, segundo entende o autor, é a origem da relação de consumo entre fornecedor e consumidor final.

Maria Eugênia Finkelstein traz um conceito bastante coerente do que seria a relação de consumo virtual, podendo as mesmas serem do tipo $B 2 B^{14}$ que "envolve relações comerciais entre empresas quanto à comercialização de produtos e prestação de serviços entre produtores, fabricantes, fornecedores e importadores, sem a participação direta do consumidor final" e as do tipo $\mathrm{B}^{2} \mathrm{C}^{15}$ que são as "relações de consumo do tipo fornecedor-consumidor" ${ }^{16}$, sendo este último tipo objeto direto do presente estudo.

\footnotetext{
12 BONATTO, Cláudio. Código de defesa do consumidor: cláusulas abusivas nas relações contratuais de consumo. 2. ed. rev. atual. Porto Alegre: Livraria do Advogado, 2004, p. 19.

13 LIMA, Eduardo Weiss Martins de. Proteção do consumidor brasileiro no comércio eletrônico internacional. - São Paulo: Atlas, 2006.

${ }^{14}$ Business to Business. Em tradução livre: Fornecedor para fornecedor.

${ }^{15}$ Business to Consumer. Em tradução livre: Fornecedor para Consumidor.

${ }^{16}$ FINKELSTEIN. Maria Eugenia Reis. Direito do comércio eletrônico. 2. ed. Rio de Janeiro: Elsevier, 2011, p. 17.

REDESG / Revista Direitos Emergentes na Sociedade Global - www.ufsm.br/redesg v. 1, n. 1, jan.jun/2012
} 
ISSN 2316-3054

Engana-se aquele que cogita ser completamente diferente a interação entre consumidor e fornecedor no comércio eletrônico. Tanto não é no todo diferente, que as figuras de consumidor - aqui tratado como e-consumer - e fornecedor - tido como e-seller ou business não tem conceito diverso daquele dado pelo CDC. Os elementos que caracterizam a relação de consumo, mesmo que virtual, permanecem os mesmos com exceção ao tipo de contrato e a forma como este é celebrado eletronicamente. ${ }^{17}$

Deste modo, além das partes do contrato eletrônico, quais sejam consumidor e fornecedor, bem como a vontade de contratar, estão presentes da mesma maneira que no contrato comum realizado por meio físico. Essencialmente, segundo Finkelstein, um contrato tradicional e um contrato eletrônico diferem basicamente na forma. ${ }^{18}$

Quando se fala na celebração do contrato eletrônico, fica-se diante da pergunta: se não diferem no todo, no que se assemelham? É bastante simples. Segundo Finkelstein aos contratos eletrônicos se aplicam as mesmas regras aplicadas aos contratos celebrados fisicamente "quanto à capacidade, objeto, causa e efeitos". ${ }^{19}$ Demais implicações emanam de codificações e leis esparsas ou então da aplicação subsidiária da legislação existente como forma de tentar suprir a lacuna legal deixada quanto à matéria.

Destaca Antonia E. L. Klee ${ }^{20}$ que os contratos virtuais de adesão podem ser tanto entre presentes quanto entre ausentes. 0 que difere nestes é o meio utilizado para a negociação. Se esta for realizada mediante oferta enviada por e-mail, e a negociação se der por este canal, é “contrato entre ausentes, porque as partes contratantes manifestam a oferta e a aceitação por meio de e-mail, havendo um lapso temporal entre a oferta e a manifestação da aceitação”. Em contrapartida, se a compra for realizada diretamente no site do fornecedor, o contrato será entendido como entre presentes, pois há comunicação imediata da compra através do clique do mouse, sendo dispensada a presença física das partes envolvidas na relação virtual de consumo.

Nesta senda, mesmo que o contrato eletrônico seja celebrado entre ausentes ou presentes, e mesmo que não seja escrito ou físico, este é perfeitamente hábil, válido e eficaz. Interessa ainda destacar que poderá vir acompanhado dos mesmos problemas dos contratos

\footnotetext{
17 SALGARELLI, Kelly Cristina. Direito do consumidor no comércio eletrônico: uma abordagem sobre a confiança e a boa-fé. $1^{\text {a }}$. ed. São Paulo: Ícone, 2010, p. 77.

${ }^{18}$ FINKELSTEIN. Maria Eugenia Reis. Direito do comércio eletrônico. 2. ed. Rio de Janeiro: Elsevier, 2011, p. 175.

${ }^{19}$ Ibidem, p. 173.

${ }^{20} \mathrm{KLEE}$, Antonia Espíndola Longoni. O Diálogo das fontes nos contratos pela internet: do vínculo contratual ao conceito de estabelecimento empresarial virtual e a proteção do consumidor. Diálogo das Fontes. Editora Revista dos Tribunais Ltda. 2012, p. 427.
}

REDESG / Revista Direitos Emergentes na Sociedade Global - www.ufsm.br/redesg v. 1, n. 1, jan.jun/2012 
ISSN 2316-3054

físicos, seja por haver cláusulas abusivas, seja pela desconfiança e vulnerabilidade ainda existente nas relações virtuais consumeristas.

$\mathrm{Na}$ visão dos doutrinadores aqui já citados, estes entendem que a relação virtual consumerista nada mais é do que a evolução de como as pessoas interagem no dia-a-dia face às novas. Isto se dá devido à facilidade de se consumir sem sair de casa.

Para se ter ideia da velocidade em que o comércio eletrônico cresce, pessoas que anteriormente tinham de se deslocar até os grandes centros para realizarem compras, atualmente o fazem em sua casa. Leva-se em conta também que a pesquisa de preços tornou-se de fácil comparação, já que há sites que agrupam diversos estabelecimentos virtuais em um só local como forma de comparar produtos iguais vendidos em diferentes lojas. Outra facilidade que o comércio eletrônico agrega é a linha direta entre consumidor e fornecedor, o que acaba por tornar os preços melhores e mais baratos do que os oferecidos no varejo e estabelecimentos físicos. $^{21}$

Outro fator determinante à "migração" dos consumidores do meio físico para o virtual é a massificação e popularização dos computadores, aliado ainda ao maior e melhor acesso da sociedade à internet, a qual hoje é oferecida a custo mais barato no Brasil devido ao projeto do Governo de levar o acesso a toda população. ${ }^{22}$

Essa massificação do comércio virtual só não é maior, segundo Finkelstein, devido a alguns empecilhos culturais. Cita a doutrinadora que a falta de confiança do consumidor em relação ao fornecedor é um dos empecilhos, já que não se vê nem se conhece pessoalmente quem é o e-seller. Vislumbra-se ainda a necessidade de melhora na infraestrutura da entrega dos bens de consumo já que o rastreamento dos produtos ainda é deficiente. ${ }^{23}$

Nesse calor exarado pela novidade que é o comércio eletrônico, destaca-se a publicidade utilizada. Salgarelli ressalta que a publicidade é fator determinante na hora de o consumidor realizar a compra na internet. Os anúncios chamativos e de cores vibrantes, aliados

\footnotetext{
${ }^{21}$ FINKELSTEIN. Maria Eugenia Reis. Direito do comércio eletrônico. 2. ed. Rio de Janeiro: Elsevier, 2011, p. 38.

${ }_{22}$ Matéria publicada no site G1, falando sobre o Plano Nacional de Banda Larga (PNBL). Disponível em <http://g1.globo.com/economia/noticia/2011/09/internet-popular-comeca-a-ser-vendida-amanha.html . Acesso em 4 de junho de 2012.

${ }^{23}$ FINKELSTEIN. Maria Eugenia Reis. Direito do comércio eletrônico. 2. ed. Rio de Janeiro: Elsevier, 2011 , p. 42.

REDESG / Revista Direitos Emergentes na Sociedade Global - www.ufsm.br/redesg v. 1, n. 1, jan.jun/2012
} 
ISSN 2316-3054

aos valores diferenciados em relação aos praticados no varejo e lojas físicas, acabam por influenciar o e-consumer a fechar a compra, bem ou serviço este muitas vezes desnecessário. ${ }^{24}$

Este furor emanado do comércio virtual acaba por tornar ainda mais vulnerável o consumidor, pois o consumidor "precisa submeter-se às regras contratuais preestabelecidas pelo fornecedor." 25 Como se trata de um contrato de adesão celebrado entre o e-consumer e o $e$ seller ou business, na maioria das vezes a compra que é realizada em um clique é desprovida de uma maior atenção do consumidor quanto ao teor das cláusulas, as quais, em muitas situações podem vir a lesar a parte mais vulnerável desta relação de consumo.

Nesta conjuntura, tem-se que os princípios que norteiam o Direito do Consumidor são a base para que as leis futuras se consolidem de forma eficaz. Para tanto, no tópico seguinte analisar-se-ão alguns dos princípios que se entendem necessários ao comércio eletrônico e às relações de consumo no meio virtual.

\subsection{Vulnerabilidade e nulidade: questões contratuais}

Com o advento do CDC, este inovou ao albergar em suas normativas a possibilidade de aplicação de alguns princípios basilares das relações consumeristas, princípios estes que, mais tarde, viriam a nortear as relações contratuais entre fornecedor e consumidor.

Vale destacar que alguns princípios têm maior destaque que outros tendo em vista sua importância e contribuição para a devida e real proteção do consumidor. O princípio da boa-fé objetiva é um destes. Merece destaque, pois, o simples conceito jurídico da boa-fé, tão somente, não seria suficiente, já que se trata na verdade de um princípio basilar das relações de consumo e imperativo para a interpretação das normas aplicáveis. ${ }^{26}$

Corroborando com o entendimento, Cláudia Lima Marques ${ }^{27}$ fortalece a ideia expondo que:

\footnotetext{
${ }^{24}$ SALGARELLI, Kelly Cristina. Direito do consumidor no comércio eletrônico: uma abordagem sobre a confiança e a boa-fé. $1^{\text {a }}$. ed. São Paulo: Ícone, 2010, p. 94.

${ }^{25} \mathrm{KLEE}$, Antonia Espíndola Longoni. O Diálogo das fontes nos contratos pela internet: do vínculo contratual ao conceito de estabelecimento empresarial virtual e a proteção do consumidor. Diálogo das Fontes. Editora Revista dos Tribunais Ltda. 2012, p. 425.

${ }^{26}$ BONATTO, Cláudio; MORAES, Paulo Valério Dal Pai. Questões controvertidas no Código de Defesa do Consumidor: principiologia, conceitos, contratos atuais. 5. ed. rev. atual. e ampl. Porto Alegre: Livraria do Advogado, 2009.

${ }^{27}$ MARQUES, Cláudia Lima. Contratos no Código de Defesa do Consumidor, 2. ed. São Paulo: Revista dos tribunais, 1995, p. 83.

REDESG / Revista Direitos Emergentes na Sociedade Global - www.ufsm.br/redesg v. 1, n. 1, jan.jun/2012
} 
ISSN 2316-3054

(...) trouxe como grande contribuição à exegese das relações contratuais no Brasil a positivação do princípio da boa-fé objetiva, como linha teleológica de interpretação, em seu art. $4^{\circ}$, III e como cláusula geral, em seu art. ${ }^{\circ} 51$, IV, positivando em todo o seu corpo de normas a existência de uma série de deveres anexos às relações contratuais.

O princípio da boa-fé objetiva é tão abrangente que alcança até mesmo outros princípios que daquele decorrem, pois não há como se falar em princípio da igualdade ou ainda da liberdade, se não for conjuntamente aplicado o da boa-fé. Pelo fato do CDC trazer à luz os direitos básicos do consumidor, e por querer igualar naturalmente os desiguais, é de suma importância que seja relacionado o princípio da igualdade, pois sem este não haveria meio para se falar em Código de Defesa do Consumidor, pois este surgiu "como forma de igualar integrantes da relação de consumo, munindo o consumidor de arma eficaz para a obtenção de respeito e, consequentemente, de força para impor sua vontade". ${ }^{28}$

Importante observar o princípio da liberdade, já que este decorre e complementa o sentido do anterior, garantindo assim a efetiva aplicação do princípio da igualdade, já que não há como se falar em liberdade contratual sem antes se falar em igualdade das partes envolvidas. Entende Bonatto, que a aplicabilidade do princípio da liberdade nas relações consumeristas é consequência lógica do princípio da igualdade já que não existe liberdade sem equidade.

Tais princípios supracitados formam os pilares necessários a orientar a correta aplicação das normas referentes às relações de consumo, tanto nos contratos físicos como nos eletrônicos, e ainda a forma como estas se dão.

Respeitável e interessante a interpretação conferida pelo CDC no que tange à vulnerabilidade do consumidor já que este, por ser parte “desigual” na relação consumerista, é vulnerável às ardilosas artimanhas e técnicas das empresas e fornecedores de bens e serviços no tocante aos contratos firmados e ainda quanto às informações e publicidades oferecidas. Com o fim de nortear e tratar com maior proteção o consumidor, aplicável se torna o princípio da vulnerabilidade, já que “o consumidor pode ser atacado de várias maneiras, sofrendo pressões que invadem a sua privacidade, na maioria das vezes sendo o alvo das maciças publicidades que criam necessidade de consumo antes inexistentes". ${ }^{29}$

\footnotetext{
${ }^{28}$ BONATTO, Cláudio; MORAES, Paulo Valério Dal Pai. Questões controvertidas no Código de Defesa do Consumidor: principiologia, conceitos, contratos atuais. 5. ed. rev. atual. e ampl. Porto Alegre: Livraria do Advogado, 2009, p. 29-30.

${ }^{29}$ Ibidem, p. 43.

REDESG / Revista Direitos Emergentes na Sociedade Global - www.ufsm.br/redesg v. 1, n. 1, jan.jun/2012
} 
ISSN 2316-3054

Em se tratando das novas tecnologias a serviço do consumo, louvável o entendimento de Newton de Lucca $^{30}$, quando este afirma:

[...] o marketing invasivo acentua-se no caso da internet, por propiciar que se faça publicidade na própria casa do consumidor, induzindo a expectativas irresistíveis de comportamentos de consumo não apenas nele, mas, igualmente, em todos os membros de sua família, gerando até mesmo conflito entre eles.

Elogiável o entendimento do doutrinador já que a vulnerabilidade do consumidor, na atualidade, estende-se até sua residência, deixando de ser um risco corrido somente nos estabelecimentos físicos de consumo, passando a integrar o cotidiano da "vida virtual" do consumidor, seja por e-mails contendo publicidade enviada pelas lojas virtuais, seja pelo caráter impessoal das relações de consumo via meio eletrônico ou ainda pela confiabilidade às cegas que o consumidor despende aos estabelecimentos eletrônicos.

Nunca antes o princípio da vulnerabilidade esteve tão evidente quanto nas atuais relações de consumo virtuais, já que além das técnicas de marketing praticadas de forma massiva na internet, os fornecedores se valem do que Bonatto ${ }^{31}$ chama de contratos estandardizados:

[...] os contratos de massa, os quais primam pela complexidade, pela tecnicidade, pela falta de esclarecimentos técnicos e profissionais específicos atinentes às suas atividades, o que induz à óbvia aceitação de que o consumidor deve ser protegido.

Deve-se ainda dar atenção ao princípio mister das relações de consumo virtuais, qual seja o da confiança. Tal princípio, dados os problemas que ainda se enfrenta no e-commerce, torna-se a principal barreira a ser quebrada na atualidade. Entende Salgarelli ${ }^{32}$ que:

É a confiança que irá tornar possível a contratação eletrônica, pois é com base na aparência do conteúdo da imagem, som, informação, no click e na presença confiável de um ser humano por trás da máquina que os negócios jurídicos se concretizarão e serão perenizados.

\footnotetext{
${ }^{30}$ DE LUCCA, Newton. Aspectos jurídicos da contratação informática e telemática. São Paulo: Saraiva, 2003 , p. 57.

31 BONATTO, Cláudio; MORAES, Paulo Valério Dal Pai. Questões controvertidas no Código de Defesa do Consumidor: principiologia, conceitos, contratos atuais. 5. ed. rev. atual. e ampl. Porto Alegre: Livraria do Advogado, 2009, p. 44.

32 SALGARELLI, Kelly Cristina. Direito do consumidor no comércio eletrônico: uma abordagem sobre a confiança e a boa-fé. São Paulo: Ícone, 2010, p. 117.
}

REDESG / Revista Direitos Emergentes na Sociedade Global - www.ufsm.br/redesg v. 1, n. 1, jan.jun/2012 
ISSN 2316-3054

Devido ao grande número de transações eletrônicas e do exponencial crescimento destas, é de se imaginar que este número somente não é maior devido a atual insegurança gerada principalmente pela dúvida, de ambos os lados - e-consumer e e-seller - em obter confiabilidade mútua. Somente não houve uma explosão de fato do consumo virtual por causa da insegurança e vulnerabilidade do consumidor frente ao fornecedor, sendo este que detém hoje toda a segurança. ${ }^{33}$

Interessante ainda notar que mesmo o fornecedor sendo a parte mais "forte" na relação de consumo eletrônica, também enfrenta problemas quanto à confiabilidade para com o consumidor, já que aquele não tem como obter a certeza e efetivação do pagamento do produto ou serviço negociado. Neste contexto, bilateral a aplicabilidade do princípio da confiança já que tanto consumidor quanto fornecedor ainda carecem de maior transparência, seja pelos meios aplicados à negociação, seja pela desconfiança mútua já conhecida em âmbito nacional e internacional das relações de consumo virtuais.

Face ao cenário atual das relações de consumo eletrônicas e diante da disparidade entre fornecedor e consumidor, surgem as cláusulas abusivas que permeiam os contratos eletrônicos. Tais cláusulas, devido muitas vezes ao não conhecimento por parte do consumidor ao contrato eletrônico firmado, acabam por gerar as chamadas cláusulas de vantagens unilaterais, pois beneficiam somente ao fornecedor que, na quase totalidade das vezes, é o único a ter acesso ao contrato de adesão firmado pela internet. Por certo, devido à alta complexidade destas, acabam por tornarem-se nulas, já que infringem descaradamente o princípio da vulnerabilidade do consumidor, ou no caso o e-consumer.

Ainda que o art. 51 trate sobre as cláusulas nulas de pleno direito, o CDC não dá um conceito específico do que seriam as chamadas cláusulas abusivas, uma interpretação interessante seria a apresentada por parte da doutrina, quando estes sugerem "como sinônimas de cláusulas abusivas as expressões cláusulas opressivas, cláusulas vexatórias, cláusulas onerosas ou cláusulas excessivas" 34 , já que aquelas não encontram caracterização no CDC, sendo que tais cláusulas, apresentando notório desfavorecimento ao consumidor, devem ser desde logo taxadas como nulas, não sendo restrito tal entendimento somente aos contratos de adesão, como também aos demais contratos de consumo, podendo estes ser escritos ou verbais.

${ }^{33}$ RELVAS, Marcos. Comércio Eletrônico: Aspectos contratuais da relação de consumo. Curitiba: Juruá, 2005, p. 77.

${ }^{34}$ BONATTO, Cláudio; MORAES, Paulo Valério Dal Pai. Questões controvertidas no Código de Defesa do Consumidor: principiologia, conceitos, contratos atuais. 5. ed. rev. atual. e ampl. Porto Alegre: Livraria do Advogado, 2009, p. 34.

REDESG / Revista Direitos Emergentes na Sociedade Global - www.ufsm.br/redesg v. 1, n. 1, jan.jun/2012 
ISSN 2316-3054

Dado o entendimento de Salgarelli ${ }^{35}$, e ainda face ao desamparo do e-consumer nas relações de consumo virtuais, tem-se que é perfeitamente aplicável o CDC aos chamados contratos eletrônicos e, por tal motivo, encontram-se subsídios capazes de estender o conceito das cláusulas abusivas também àqueles, tornando plenamente nulas quaisquer cláusulas que possam vir a obstar, lesar ou vexar o e-consumer.

\section{PREMISSAS LEGAIS: O ANTEPROJETO DE ATUALIZAÇÃO DO CÓDIGO DE DEFESA DO CONSUMIDOR E O TJRS FRENTE ÀS LACUNAS JURÍDICAS DO E- COMMERCE}

Como exarado anteriormente, tem-se que o atual CDC é perfeitamente aplicável às relações consumeristas no meio virtual. Porém, mesmo que possam ser estendidas ao comércio eletrônico, as tratativas elencadas no CDC fazem menção apenas às relações de consumo realizadas fisicamente, quando as partes estão presentes ou ainda, quando entre ausentes, mas havendo conhecimento da localização das partes e possíveis encontros futuros para acertar o negócio realizado.

Por esta razão, o CDC irá passar por uma alteração, a qual é tratada no Anteprojeto de Atualização do Código de Defesa do Consumidor, a fim de embarcar na proteção oferecida por este os também consumidores eletrônicos e as relações virtuais de consumo, sejam elas via $e$ mail, site ou telefone. Essa atualização não é uma ideia recente, pois a preocupação em regulamentar o comércio eletrônico emana de tempos anteriores até mesmo ao CDC.

A fim de adentrar e fazer um apanhado histórico das proposições já realizadas para a regulamentação do comércio eletrônico, necessário que trate da Lei Modelo da United Nations Comission in International Trade Law (UNCITRAL) ${ }^{36}$ sobre o e-commerce. Sabe-se que desde a década de 1970 há uma preocupação, em escala internacional, de regular as relações que se dão por meio virtual. A lei modelo apresentada pela UNCITRAL em 1996, destaca-se por ser a principal base utilizada pelas atuais legislações existentes sobre a matéria do comércio eletrônico no mundo. ${ }^{37}$

\footnotetext{
${ }^{35}$ SALGARELLI, Kelly Cristina. Direito do consumidor no comércio eletrônico: uma abordagem sobre a confiança e a boa-fé. São Paulo: Ícone, 2010.

${ }^{36} \mathrm{Em}$ tradução livre: Comissão de Direito em Comércio Internacional das Nações Unidas.

${ }^{37}$ FINKELSTEIN. Maria Eugenia Reis. Direito do comércio eletrônico. 2. ed. Rio de Janeiro: Elsevier, 2011, p. 72.

REDESG / Revista Direitos Emergentes na Sociedade Global - www.ufsm.br/redesg v. 1, n. 1, jan.jun/2012
} 
ISSN 2316-3054

É de se salientar que esta lei toma por base regular o comércio eletrônico internacional entre os membros das Nações Unidas, sendo apenas um "norte” para a criação de leis que possam viabilizar o e-commerce mais seguro e confiável. Tem-se aqui uma espécie de marco pioneiro de tentativa de regulamentação do comércio eletrônico. A partir da lei modelo apresentada pela UNCITRAL, diversos outros órgãos internacionais começaram a desenvolver suas próprias alternativas ou ideias quanto à regulamentação legal do comércio eletrônico. Podem-se citar alguns importantes: Organização Mundial do Comércio (OMC) e a Conferência Ministerial de 2001 realizada no Qatar que ratificou o programa de pesquisa da OMC a cerca do e-commerce; a Organisation for Economic Co-operation and Development (OECD) ${ }^{38}$ bem como diversas outras legislações esparsas que surgiram em diversos países, as quais não serão objeto deste estudo por tratarem de tema mais amplo. ${ }^{39}$

Vale, contudo, destacar a chamada E-Lex Mercatoria, esta proposição traz como premissa a uniformização das leis que tratem do comércio eletrônico, através de um compilado destas aplicáveis aos Estados soberanos que venham a aderir àquela. Entende Finkelstein que "a aplicação da Lex mercatoria para solver disputas derivadas de questões originadas em operações comerciais eletrônicas internacionais pode vir a ser uma boa opção para dirimir tais conflitos”40 , ou seja, uma uniformização viria facilitar as relações comerciais internacionais. Há, entretanto, segundo a autora, uma relutância em aceitar tal proposta, visto que as doutrinas não são uniformes.

Em âmbito nacional, à sombra do que fora proposto durante vários anos pelas organizações mencionadas anteriormente, existem alguns Projetos de Lei sobre o Comércio Eletrônico que valem ser citadas. Finkelstein ${ }^{41}$ elenca estes como sendo: o Projeto de Lei $n^{\circ}$ 1.589 de 1999² ; Projeto de Lei $n^{\circ} 672$ de 199943; Projeto de Lei $n^{\circ} 1.483$ de $1999^{44}$. Além destes, existem outras que tratam de alguns bens e serviços específicos que não são importantes nesse

\footnotetext{
${ }^{38}$ Em tradução livre: Organização de Cooperação e de Desenvolvimento Econômico.

39 LIMA, Eduardo Weiss Martins de. Proteção do consumidor brasileiro no comércio eletrônico internacional. - São Paulo: Atlas, 2006.

${ }^{40}$ FINKELSTEIN. Maria Eugenia Reis. Direito do comércio eletrônico. 2. ed. Rio de Janeiro: Elsevier, 2011, p. 50 .

${ }_{41}^{4}$ Ibidem, p. 57-58

${ }^{42}$ Fora apensado ao Projeto de Lei n ${ }^{\circ} 1483 / 99$ em 24 de setembro de 1999.

${ }^{43}$ Arquivado em 16 de maio de 2005 . Houve posterior pedido de desarquivamento, o qual fora negado em 2007.

${ }^{44}$ Fora apensado ao Projeto de Lei $n^{\circ} 4906 / 2001$ em 25 de junho de 2001. Não vingou, pois este fora arquivado em fevereiro de 2007.
}

REDESG / Revista Direitos Emergentes na Sociedade Global - www.ufsm.br/redesg v. 1, n. 1, jan.jun/2012 
ISSN 2316-3054

estudo, já que se procura abordar aqui as relações de consumo virtuais e não o comércio eletrônico como um todo.

Neste contexto, para melhor abordar o tema, passa-se a análise do anteprojeto de atualização do CDC e posteriormente o posicionamento do TJRS em algumas decisões no que tange ao tema.

\subsection{Anteprojeto de atualização do Código de Defesa do Consumidor}

O Anteprojeto de Atualização do CDC busca estender as garantias ofertadas ao consumidor comum também ao e-consumer e regular os deveres dos fornecedores que utilizam a internet ou outro meio tecnológico para realização de seus negócios. Assim, Newton de Lucca $^{45}$ aduz:

Aplicar-se-á total ou parcialmente o CDC às relações jurídicas, dependendo de serem ou não os sujeitos atuantes nessas relações, fornecedores e consumidores. Identificados como tais, razão nenhuma existe para que thes sejam criados óbices à plena aplicação da legislação tutelar.

Essa atualização se dá porque a relação de consumo virtual não difere da relação de consumo física, senão pela forma da celebração do contrato de adesão e o local. Para tanto, o legislador brasileiro busca agora regular as relações virtuais consumeristas, a fim de suprir a lacuna quanto ao Comércio Virtual revisando alguns artigos da Lei 8.079/90 (Código de Defesa do Consumidor).

A Comissão de Juristas que elaborou as modificações presentes no Anteprojeto de Atualização do CDC justificou as alterações aduzindo que:

[...] As normas projetadas visam a preparar o mercado e a sociedade brasileira para a evolução tecnológica dos próximos anos, respeitando as condições estruturais e culturais brasileiras. Reforçam, a exemplo do que já foi feito na Europa, os direitos de informação, transparência, lealdade, cooperação e segurança nas relações do comércio eletrônico, complementando as normas já trazidas pelo Código Civil de 2002, doravante reforçadas para a proteção dos consumidores.

A proposta atualiza as normas já existentes no CDC, em matéria de oferta, assegurando maior informação, acesso e possibilidade de perenização das manifestações e dos contratos eletrônicos realizados com consumidores. Lista novas práticas abusivas já existentes no mercado, consolidando o direito de

45 DE LUCCA, Newton. Aspectos jurídicos da contratação informática e telemática. São Paulo: Saraiva, 2003, p. 410. 


\begin{abstract}
arrependimento nesses contratos, assim como regula e facilita a possibilidade de retificação de erros na contratação. Trata, igualmente, de temas conexos, como os contratos coligados de crédito e o pagamento pelo produto ou serviço fornecido a distância; a proteção dos dados do consumidor e de sua privacidade, instituindo e reforçando a possibilidade de o consumidor optar por não receber spam e telemarketing.

A evolução do uso comercial da internet, se, por um lado, traz inúmeros benefícios, por outro, amplia a vulnerabilidade do consumidor. Assim, é essencial que se cumpra o comando constitucional do art. $5^{\circ}, \mathrm{XXXII}$, e do art. 170, V, da Constituição Federal, e se criem regras que, efetivamente, ampliem a sua proteção no comércio eletrônico, a fim de que a evolução tecnológica alcance os objetivos que todos desejam: o desenvolvimento social e econômico e o aperfeiçoamento das relações de consumo. ${ }^{46}$
\end{abstract}

Neste contexto, verifica-se que o objetivo da atualização proposta é ampliar a proteção ao e-consumer e adaptar o CDC aos novos métodos aplicados ao comércio em âmbito eletrônico, seja na questão de direitos referentes ao consumidor final, seja quanto aos deveres dos fornecedores virtuais. Tendo isto em mente, vislumbra-se que se busca minimizar a vulnerabilidade do consumidor que, na internet, torna-se ainda mais hipossuficiente frente ao fornecedor, pois a compra em meio eletrônico ocorre na maioria das vezes “às cegas” por não conhecer quem está do outro lado da relação jurídica.

Com um olhar mais a fundo, importante a análise singular de cada um dos artigos a que foram propostas modificações. Dessa forma, passa-se a analisar o anteprojeto de atualização do CDC.

A primeira delas acontece justamente no artigo primeiro do CDC acrescentando ao mesmo dois parágrafos, dos quais se transcreve o primeiro: “As normas e os negócios jurídicos devem ser interpretados e integrados da maneira mais favorável ao consumidor" (Parágrafo $1^{\circ}$ acrescentado ao art. $1^{\circ}$ do CDC através da atualização proposta). 0 parágrafo em destaque traduz a premissa máxima do CDC, qual seja a proteção ao consumidor da forma que the seja mais benéfica, ou seja, encarando este como a parte mais vulnerável da relação de consumo mesmo que virtual.

Outro artigo ao qual fora proposta modificação é o art. $5^{\circ}$ o qual se transcreve a seguir: "Para a execução da Política Nacional das Relações de Consumo, contará o poder público com os seguintes instrumentos, entre outros" ${ }^{47}$. Segundo o proposto, seriam acrescentados quatro incisos, destacando-se o que prevê "o cadastro de bloqueio de recebimento de oferta ou

\footnotetext{
${ }^{46}$ Anteprojeto de Atualização do Código de Defesa do Consumidor. Arquivo em PDF disponível em: <http://www.iabnacional.org.br/article.php3?id_article=1366 > Acesso em 06 de junho de 2012. ${ }^{47}$ Disponível em <http://www.planalto.gov.br/ccivil_03/leis/L8078.htm>. Acesso em: 6 jun. 2012.

REDESG / Revista Direitos Emergentes na Sociedade Global - www.ufsm.br/redesg v. 1, n. 1, jan.jun/2012
} 
ISSN 2316-3054

comunicação telefônica, eletrônica ou de dados" (Inciso VI sugerido ser incluso ao art. $5^{\circ}$ do CDC pelo anteprojeto de atualização). Este novo inciso oferece melhor proteção ao consumidor virtual no que tange ao "ataque maciço" perpetrado pelos estabelecimentos virtuais utilizandose de e-mails publicitários bem como dos envios de promoções via correio. É de extrema importância este novo inciso já que a massificação do marketing virtual é evidente no comércio eletrônico como um todo.

Cabe evidenciar que fora ainda proposto o inciso XII ao artigo $6^{\circ}$ do CDC. Este inciso remete ao inciso $\mathrm{VI}$ sugerido ao art. $5^{\circ}$, trazendo o bloqueio de ofertas e publicidade pelo meio eletrônico como um dos direitos básicos do consumidor. A alteração sugerida a este artigo do CDC inclui também outros direitos básicos do consumidor, quais sejam:

\begin{abstract}
XI - a segurança e a privacidade de comunicação, oferta, cadastro ou qualquer operação por meio eletrônico, preservada a confidencialidade das informações e dados prestados ou coletados;

XII - a inscrição em cadastro de bloqueio de recebimento de oferta ou comunicação telefônica, eletrônica ou de dados;

XIII - a garantia de práticas de crédito responsável, prevenção e tratamento das situações de superendividamento do consumidor pessoa física;

XIV - a prevenção do superendividamento e proteção do consumidor pessoa física de boa-fé, preservando o mínimo existencial, por meio da revisão e repactuação da dívida, dentre outras medidas;

XV - a confirmação pelo fornecedor de recebimento da manifestação do consumidor de aceitação da oferta, inclusive eletrônica, de produtos ou serviços. ${ }^{48}$
\end{abstract}

No que tange à modificação do art. $7^{\circ}$, previu a Comissão de Juristas a inclusão de um segundo parágrafo ${ }^{49}$, o qual assegura a aplicação da norma mais favorável ao consumidor, seja ela objeto de tratados ou convenções internacionais que o Brasil seja signatário, legislação ordinária interna ou regulamentos expedidos pelas autoridades competentes. Reafirma-se com a inclusão deste inciso, a interpretação mais benéfica possível das normas ao consumidor, seja ele virtual ou não.

Impende ainda salientar alguns parágrafos do art. 33 que tem conexão com o presente estudo. Dentre eles, merece destaque o parágrafo $2^{\circ}$ que veda a onerosidade da oferta de produtos ou serviços ao consumidor pelo meio eletrônico. Não faria sentido onerar o consumidor

\footnotetext{
${ }^{48}$ Incisos sugeridos de inclusão ao CDC pelo anteprojeto de atualização. Arquivo em PDF disponível em: <http://www.iabnacional.org.br/article.php3?id_article=1366 > Acesso em: 6 jun. 2012.

$49 \S 2^{\circ}$ Aplica-se ao consumidor a norma mais favorável ao exercício de seus direitos e pretensões. Disponível em: <http://www.iabnacional.org.br/article.php3?id_article=1366> Acesso em: 6 jun. 2012.

REDESG / Revista Direitos Emergentes na Sociedade Global - www.ufsm.br/redesg v. 1, n. 1, jan.jun/2012
} 
ISSN 2316-3054

por algo que não solicitou, já que a ocorrência da propagação em massa de ofertas via e-mail é algo hoje massificado e, na maioria das vezes, sem o consentimento do consumidor.

Quanto à oferta em si, destaca-se o parágrafo $3^{\circ}$ o qual trata que a oferta deverá vir acompanhada do nome empresarial e número da inscrição no Ministério da Fazenda, um resumo da segurança oferecida, endereços geográficos - endereço físico - bem como o eletrônico do estabelecimento, números de telefone e e-mail e página na internet para atendimento ao consumidor e opção de bloqueio de novas comunicações ao consumidor, sejam elas publicitárias ou não. Tais considerações servem para ampliar a segurança bem como a proteção dos dados cadastrais dos consumidores, dados estes que poderiam gerar um estudo único sobre eles.

De fato, o art. 33 que anteriormente possuía um único parágrafo, pela proposta do anteprojeto passaria a ter seis parágrafos, os quais foram transcritos em nota. Vale, porém, destacar ainda que os parágrafos quarto, quinto e sexto visam resguardar os dados do negócio ou contrato virtual celebrado, bem como os dados do consumidor virtual, aduzindo ainda que o fornecedor deverá assegurar a mantença das informações referentes à compra, características da oferta, preços e condições de pagamento.

Em se tratando da segurança do e-consumer, cabe salientar o art. 39 do CDC que traz as vedações às práticas abusivas. Optou a Comissão que propõe a atualização do código protetivo por incluir dois incisos ao rol das práticas abusivas, sendo que o inciso XIV sugere a vedação de oferta de bem ou serviço, bem como a comunicação de qualquer espécie ao consumidor inscrito em cadastro de bloqueio. Por sua vez, o inciso XV fora proposto da seguinte forma:

\footnotetext{
Veicular, hospedar, exibir, licenciar, alienar, utilizar, compartilhar, doar ou de qualquer forma ceder ou transferir dados ou informações pessoais ou identificadoras de consumidores sem a sua expressa autorização e consentimento informado, salvo regular alimentação de banco ou cadastro destinado à proteção ao crédito. ${ }^{50}$
}

Os incisos sugeridos pela Comissão ao art. 39 viabilizam, além da privacidade do consumidor, também a segurança de seus dados, sejam eles cadastrais, pessoais ou informativos.

Ainda no que concerne à privacidade e segurança dos dados do consumidor, importa destacar a criação do art. 72-A, o qual dispõe sobre a penalidade imposta àqueles que violarem o disposto no novo inciso XV do art. 39, aplicando a pena de detenção de seis meses a dois anos e multa aos fornecedores ou equivalentes que praticarem a conduta lesiva.

\footnotetext{
${ }^{50}$ Disponível em: <http://www.iabnacional.org.br/article.php3?id_article=1366 > Acesso em: 6 jun. 2012. REDESG / Revista Direitos Emergentes na Sociedade Global - www.ufsm.br/redesg v. 1, n. 1, jan.jun/2012
} 
ISSN 2316-3054

No que tange ao direito de arrependimento, novamente inteligentes as alterações propostas ao retirar do art. 49, caput do CDC, a limitação quanto ao prazo ser praticável somente nas contratações realizadas em domicílio ou telefone, pois se ampliou a aplicabilidade do direito de arrependimento a toda e qualquer relação de consumo ou contratação realizada a distância. Nas atualizações propostas a este artigo, se sobressai a que fala sobre a devolução da quantia paga imediatamente quando exercido o arrependimento no prazo de sete dias, devendo ainda os valores serem monetariamente atualizados.

Cabe ainda tecer comentários no que concerne à inserção do inciso XIII ao rol das multas e penalidades impostas aos fornecedores que não se adaptem ao CDC e suas normativas, ao passo além das já presentes, soma-se a "suspensão temporária ou proibição de oferta e de comércio eletrônico" ${ }^{51}$. Este viabiliza penalizar o fornecedor que não respeitar o desejo do consumidor em não mais receber qualquer tipo de oferta ou comunicação, seja via e-mail, telefone ou qualquer outro meio eletrônico. Novamente, buscam os integrantes da Comissão de atualização, resguardar a privacidade do consumidor.

Por fim, quanto às infrações e penalidades referentes às infrações cometidas em âmbito das relações de consumo, vale destacar a proposta de inclusão de um quarto parágrafo ao art. 59, aduzindo ser necessária a notificação dos provedores de serviço de conexão, hospedagem e armazenagem de sites que, no prazo máximo de quarenta e oito horas. Deverão nesse prazo, efetuar o bloqueio e/ou exclusão da conexão e hospedagem a fim de fazer valer a sanção da proibição da oferta e do comércio eletrônico.

Para bem fechar a proposta de atualização do CDC, sugeriu a Comissão do Anteprojeto a inclusão de dois parágrafos ao art. 101 do código protetivo, o qual trata da ação de responsabilidade civil do fornecedor de produtos e serviços acrescentando a previsão daquela ser viável quanto às relações de consumo em âmbito eletrônico, estabelecendo que no caso de fornecimento à distância, a ação poderá ser proposta no domicílio do consumidor e que são nulas as cláusulas que prevêem eleição de foro e arbitragem. Estas imposições buscam viabilizar uma melhor defesa do consumidor devido à vulnerabilidade do e-consumer ao realizar negócios pela internet.

\subsection{Tribunal de Justiça do Rio Grande do Sul frente ao comércio eletrônico}

\footnotetext{
51 Inciso XIII sugerido ao artigo 56 do CDC através do anteprojeto de atualização. Disponível em: <http://www.iabnacional.org.br/article.php3?id_article=1366 > Acesso em: 6 jun. 2012.

REDESG / Revista Direitos Emergentes na Sociedade Global - www.ufsm.br/redesg v. 1, n. 1, jan.jun/2012
} 
Sabe-se que a aplicabilidade do Código de Defesa do Consumidor, mesmo que de forma a "mascarar" as lacunas deixadas pelo legislador quanto às relações de consumo virtuais, é perfeitamente plausível. Para demonstrar a perfeita utilização do CDC no intuito de dirimir conflitos resultantes das relações de consumo em âmbito eletrônico, passa-se a analisar o posicionamento do Tribunal de Justiça do Rio Grande do Sul (TJRS), a partir de quatro decisões que compreendem o tema.

Para bem exemplificar a possibilidade da aplicação do CDC às relações de consumo virtuais, decidiu o TJRS recentemente que o site Mercado Livre possuía responsabilidade civil objetiva e solidária, quanto ao não recebimento do produto adquirido pelo recorrente com vendedor cadastrado no respectivo site. Aduziu o relator ser perfeitamente aplicável ao caso em tela o CDC, pois se trata de relação de consumo, mesmo que a remuneração entre o recorrente e o recorrido seja indireta. A fim de melhor entender o caso, transcreve-se a ementa:

Ementa: APELAÇÃO CÍVEL. RESPONSABILIDADE CIVIL. APLICABILIDADE DO CÓDIGO DE DEFESA DO CONSUMIDOR. INTERNET. SITE DE COMPRA EVENDA VIRTUAL "MERCADO LIVRE". VENDEDOR CADASTRADO QUE RECEBE O PAGAMENTO E NÃO ENVIA O PRODUTO AO COMPRADOR. ATO ILÍCITO CONFIGURADO. DEFEITO DO SERVIÇO. DANOS MATERIAIS COMPROVADOS. DANOS MORAIS INOCORRENTES. APLICAÇÃO DO CÓDIGO DE DEFESA DO CONSUMIDOR - Aplicável ao caso o Código de Defesa do Consumidor, embora a relação estabelecida entre a autora e o réu não ocorra mediante remuneração direta, ou seja, o pagamento por aquela pelo serviço disponibilizado por este. Ocorre que o conceito de remuneração, para fins de aplicação do art. $3^{\circ}$, $\S 2^{\circ}$, do CDC, permite interpretação mais ampla, em favor do consumidor, para abranger a remuneração indireta, como acontece na espécie, em que o requerido não recebe valores diretamente do autor, mas do vendedor que realizou negócio de compra e venda com o autor por intermédio de anúncio de produto à venda em seu sítio eletrônico. Há uma remuneração do serviço prestado pela demandada, pois os Termos e Condições Gerais de Uso do Mercado Livre estabelece que o vendedor pagará comissão pela negociação concretizada, dentre outras formas de remuneração. Assim, o autor paga, ainda que indiretamente, pelo serviço prestado pela demandada, pois ao vendedor impõe-se o pagamento de uma comissão pelo negócio concretizado. RESPONSABILIDADE CIVIL OBJETIVA DO SITE DE INTERMEDIAÇÃO DE COMPRA E VENDA VIRTUAL - Há responsabilidade objetiva da empresa bastando que exista, para caracterizá-la, a relação de causalidade entre o dano experimentado pela vítima e o ato do agente, surgindo o dever de indenizar, independentemente de culpa ou dolo. 0 fornecedor de produtos e serviços responde, independentemente da existência de culpa, pela reparação dos danos causados por defeitos relativos aos produtos e prestação de serviços que disponibiliza no mercado de consumo. A empresa responde pelos danos quando disponibiliza 
ISSN 2316-3054

\begin{abstract}
serviço defeituoso no mercado de consumo. Caso em que se evidenciou o defeito do serviço, em razão da não entrega de produto anunciado no site de compra e venda virtual da demandada, cujo pagamento do preço fora devidamente efetuado pelo autor. Ato ilícito configurado. Responsabilidade pelo defeito no serviço de intermediação de compra e venda virtual colocado no mercado de consumo pela demandada Mercado Livre. Comprovados os danos materiais, nos termos dos artigos 927 e 944 do CC, deve a ré indenizar os prejuízos suportados pelo consumidor. - DANOS MORAIS - INOCORRENTES - Não é todo descumprimento contratual que implica o dever de indenização por danos morais. Hipótese dos autos em que não há prova de que os danos realmente tenham ocorrido. Meros dissabores, sem prova do efetivo abalo à esfera jurídica do consumidor, não ensejam o dever de indenizar. Precedentes. PREQUESTIONAMENTO - O julgador não está obrigado a rebater todos os argumentos, tampouco mencionar todos os dispositivos constitucionais e legais elencados pelo recorrente, bastado declinar os motivos que fundamentam a decisão. APELO PARCIALMENTE PROVIDO. ${ }^{52}$
\end{abstract}

Vislumbra no caso acima que, mesmo a oferta veiculada por terceiro contratante do serviço de hospedagem, vincula o proprietário e administrador do site que concentra os vendedores, pois entende o TJRS que a responsabilidade é extensiva porquanto o site que mantém a oferta do vendedor no ar recebe comissão das vendas realizadas em seu domínio. Evidente assim e sem sombra de quaisquer dúvidas, a aplicação do Código de Defesa do Consumidor ao caso apresentando.

Seguindo a mesma linha do acórdão acima, transcreve-se a seguinte ementa:

Ementa: RESPONSABILIDADE CIVIL. COMERCIO ELETRONICO. FRAUDE NA COMPRA E VENDA PELA INTERNET. RESPONSABILIDADE DA ADMINISTRADORA DO SITE DE ANÚNCIOS. CONFERÊNCIA DOS DADOS DOS ANUNCIANTES. AUSÊNCIA DE CAUTELA PELA ADMINISTRADORA. CULPA EVIDENCIADA. DANOS MORAIS CARACTERIZADOS. DEVOLUÇÃO DOS VALORES DESEMBOLSADOS. 1. Possui legitimidade o banco demandado para responder a ação na medida em que a empresa denominada Webmotors, com a qual o autor efetuou o negócio jurídico, é de sua propriedade, conforme documento juntado à fl. 31 dos autos, fato que sequer restou contestado. Da mesma forma, não se pode imputar a responsabilidade a terceiro, tendo em vista que agiu o banco de forma negligente ao permitir a divulgação de anúncios falsos em seu domínio. 2. A aplicação do Código de Defesa do Consumidor tem lugar quando caracterizada a condição de fornecedor. Hipótese em que o administrador do site de anúncios percebe remuneração pela atividade, ainda que indiretamente, atuando como intermediário na compra e venda. 3. Fraude praticada por terceiros, através da veiculação de anúncio falso no domínio administrado pelo réu. Procedimento

\footnotetext{
${ }^{52}$ Apelação Cível № 70042195354, Nona Câmara Cível, Tribunal de Justiça do RS, Relator: Leonel Pires Ohlweiler, Julgado em 10/08/2011. Disponível em: http://www1.tjrs.jus.br. Acesso em: 6 jun. 2012.

REDESG / Revista Direitos Emergentes na Sociedade Global - www.ufsm.br/redesg v. 1, n. 1, jan.jun/2012
} 
ISSN 2316-3054

\begin{abstract}
que além de causar dissabor e transtorno, com quebra da tranqüilidade e da paz diuturna do cidadão, agride sua dignidade pessoal, mormente pela impotência de resolver o problema mediante contato direto com o demandado. Tais acontecimentos são suficientes a colorir a figura do dano moral, cabendo uma compensação pelos transtornos sofridos, que efetivamente ultrapassam a barreira daquilo que se entende por socialmente suportável por parte do cidadão comum. 4. O valor da compensação deve compreender, dentro do possível, a reparação pelo dano infligido a vitima, ao mesmo tempo servindo de freio, de elemento inibidor e de sanção ao autor do ato ilícito, a fim de que não o volte a repetir. Hipótese em que o quantum vai fixado em $R \$ 6.000,00$, porque consentâneo com a realidade do caso concreto e com os parâmetros utilizados por esta Câmara. 5. Cabível a devolução dos valores desembolsados em razão da fraude que vitimou o autor, consoante comprovantes de depósitos juntados aos autos. 6. Honorários advocatícios que vão fixados em $15 \%$ sobre o valor da totalidade da condenação, já que o montante guarda correspondência com as operadoras do art. $20, \S 3^{\circ}$, do CPC, além de bem remunerar o profissional em atuação neste feito. ${ }^{53}$
\end{abstract}

Semelhante ao caso anterior, porém mais antigo, o recurso em tela buscava a responsabilização do administrador do site que hospedava a oferta do produto de um fornecedor. A justificativa apresentada pelo recorrido era que de o mesmo somente prestava serviço ao fornecedor, o qual "alugava” o espaço virtual para realizar suas vendas sem, no entanto, haver responsabilização extensiva ao administrador do site por eventuais vícios ou problemas na relação contratual efetivada. Entendeu o legislador, porém, que mesmo o site sendo mero "espaço virtual" alugado ao vendedor, aquele lucrava com as vendas deste pelo fato de serem pagas comissões, agindo como intermediário na compra e venda no meio eletrônico.

No mesmo andar das decisões acima referidas, entendeu o TJRS no acórdão $\mathrm{n}^{\circ}$ $70033144437^{54}$, que o site Mercado Livre é parte da relação de consumo face ao fato deste funcionar como intermediador da venda entre um determinado fornecedor e o e-consumer. Entendeu o relator que mesmo o réu (Mercado Livre) sendo apenas mantenedor do espaço virtual, este é solidariamente responsável pelas avenças que venham a ocorrer nas relações de

\footnotetext{
${ }^{53}$ Apelação Cível № 70030405534, Décima Câmara Cível, Tribunal de Justiça do RS, Relator: Paulo Antônio Kretzmann, Julgado em 26/11/2009. Disponível em http://www.tjrs.jus.br. Acesso em: 06 de junho de 2012.

${ }^{54}$ Brasil. Apelação cível. Responsabilidade civil. Danos morais. Preliminar de cerceamento de defesa afastada. Manutenção de cadastro. Comércio eletrônico. "mercado livre". Venda de "notebook" via internet. Não recebimento dos valores. Legitimidade do site que disponibiliza a realização de negócios e recebe uma comissão do anunciante, quando concretizado o negócio. Devolução da quantia paga. Sucumbência redimensionada. Afastaram as preliminares, e no mérito, deram parcial provimento ao apelo. Unânime. (Apelação cível $N^{\circ} 70033144437$, sexta câmara cível, tribunal de justiça do rs, relator: léo romi pilau júnior, julgado em 27/10/2011). Disponível em: www1.tjrs.jus.br. Acesso em: 20 jun. 2012.

REDESG / Revista Direitos Emergentes na Sociedade Global - www.ufsm.br/redesg v. 1, n. 1, jan.jun/2012
} 
ISSN 2316-3054

consumo ali perpetradas devido ao lucro que este obtém nas comissões ganhas por cada venda realizada através de seu site. Restou, portanto, segundo o relator, configurada a aplicabilidade do CDC porquanto o réu se caracteriza como fornecedor.

Existem outras decisões com similar entendimento no TJRS. Esses tantos outros acórdãos corroboram uns aos outros quanto à aplicabilidade do CDC ao comércio eletrônico mesmo que não haja no texto legal a previsão deste. Para bem confirmar o exarado, basta realizar uma busca por outras jurisprudências abrangendo o tema do presente estudo - comércio virtual - ir-se-á encontrar posicionamentos já consolidados quanto à caracterização da relação virtual de consumo inclusa no rol protetivo do CDC.

Neste sentido seguem as recentes decisões do TJRS quanto à aplicabilidade do Código de Defesa do Consumidor às relações virtuais de consumo, mesmo que tal aplicação seja ainda permeada de lacunas para as quais se busca o devido preenchimento com a realização da atualização proposta pela Comissão de Juristas do CDC no anteprojeto de atualização.

\section{CONCLUSÃO}

Como presenciado ao longo deste estudo, fica clara a proteção conferida pelo CDC aos consumidores virtuais, mesmo que de forma subsidiária. Com o crescimento da internet no país e no mundo, facilitou-se a propagação do comércio eletrônico em escala quase que instantânea. Ao longo da vigência do código de defesa do consumidor, ficaram claras as lacunas deixadas pelo legislador quanto ao tema, pois a evolução social se dá de forma mais veloz que a do direito em si.

Diante das lacunas que permeiam o CDC quanto ao comércio eletrônico, diversas são as iniciativas - doutrinárias e legais - a fim de regulamentar este novo meio de interação entre fornecedor e consumidor. Para tanto, existem projetos de leis que buscam sanar o vazio legal deixado pelo legislador quando da edição das leis vigentes. Ao longo deste estudo, abordou-se de forma mais específica o anteprojeto de atualização do CDC, o qual abarca em seu rol diversas sugestões - ou tentativas - de artigos e incisos buscando alcançar a proteção conferida neste código ao consumidor em âmbito virtual.

Abordou também o presente estudo, as questões que inviabilizam até o momento, uma maior expressividade desta nova modalidade de relação consumerista, ao passo que a confiança 
ISSN 2316-3054

do consumidor em relação ao fornecedor e a boa-fé deste para com aquele, ainda são alguns dos percalços a serem vencidos e melhor protegidos.

Pelo exposto, entende-se que a falta de confiança do consumidor já presente nas relações de consumo comuns, aumenta na medida em que na rede mundial de computadores as práticas abusivas perpetradas pelos fornecedores são ainda maiores face à contratação realizada por meio do computador, sem haver o contato direto entre o que fornece e o que consome.

Denota-se que a facilitação do acesso à internet é inviável na medida em que a proteção daqueles que utilizam essa ferramenta para realizar compras é carente e deficiente no âmbito legal e protetivo.

Nesta conjuntura, importante o estudo realizado quanto ao tema e também as arguições realizadas já que, com a era digital batendo às portas das residências de cada cidadão consumidor, imperioso que os legisladores brasileiros fomentem entre si possibilidades e sugestões a fim de sanar as lacunas legais presentes no atual CDC, as quais carecem de entendimento inovador daqueles que labutam a aplicação e a interpretação do direito.

\section{REFERÊNCIAS}

BONATTO, Cláudio. Código de defesa do consumidor: cláusulas abusivas nas relações contratuais de consumo. 2. ed. rev. atual. Porto Alegre: Livraria do Advogado, 2004.

BONATTO, Cláudio; MORAES, Paulo Valério Dal Pai. Questões controvertidas no Código de Defesa do Consumidor: principiologia, conceitos, contratos atuais. 5. ed. rev. atual. e ampl. Porto Alegre: Livraria do Advogado, 2009.

DE LUCCA, Newton. Aspectos jurídicos da contratação informática e telemática. São Paulo: Saraiva, 2003

; FILHO, Adalberto Simão (coordenadores). Direito e internet vol. II: Aspectos Jurídicos Relevantes. São Paulo: Quartier Latin, 2008.

FINKELSTEIN. Maria Eugenia Reis. Direito do comércio eletrônico. 2. ed. Rio de Janeiro: Elsevier, 2011

KLEE, Antonia Espíndola Longoni. O Diálogo das fontes nos contratos pela internet: do vínculo contratual ao conceito de estabelecimento empresarial virtual e a proteção do consumidor. DIÁLOGO DAS FONTES. São Paulo: Revista dos Tribunais, 2012.

LIMA, Eduardo Weiss Martins de. Proteção do consumidor brasileiro no comércio eletrônico internacional. São Paulo: Atlas, 2006. 
ISSN 2316-3054

LIMBERGER, Têmis. 0 direito à intimidade na era da informática: a necessidade de proteção dos dados pessoais. Porto Alegre: Livraria do Advogado, 2007.

MARQUES, Cláudia Lima. Contratos no Código de Defesa do Consumidor, 2. ed. São Paulo: Revista dos tribunais, 1995.

Confiança no Comércio Eletrônico e a Proteção do Consumidor: um estudo dos negócios jurídicos de consumo no comércio eletrônico. São Paulo: Revista dos Tribunais, 2004.

MATTE, Mauricio de Souza. Internet: Comércio Eletrônico - Aplicabilidade do Código de Defesa do Consumidor nos contratos de e-commerce. São Paulo: LTr, 2001.

MORAES, Paulo Valério Dal Pai. Código de Defesa do Consumidor - o princípio da vulnerabilidade no contrato, na publicidade, nas demais práticas comerciais: interpretação sistemática do direito. 3. ed., rev., atual. Porto Alegre: Livraria do Advogado, 2009.

RELVAS, Marcos. Comércio Eletrônico: Aspectos contratuais da relação de consumo. Curitiba: Juruá, 2005.

SALGARELLI, Kelly Cristina. Direito do consumidor no comércio eletrônico: uma aborda sobre a confiança e a boa-fé. São Paulo: Ícone, 2010.

TELLINI, Denise Estrella. Regime de Direito Internacional Privado na responsabilidade dos provedores de internet: (Content Services Providers e Intermediary Service Providers) pela qualidade dos serviços executados online. Porto Alegre: Sergio Antonio Fabris, 2006.

VOLPI NETO, Angelo. Comércio Eletrônico - Direito e Segurança. 1 ed. 9 reimpressão. Curitiba: Juruá, 2011. 